\title{
Strategi Branding Pesisir Pantai Kota Surabaya Sebagai Potensi Wilayah Berbasis Kelautan
}

\author{
Aryo Bayu Wibisono, Albert Daniel Pattisellano, dan Aphief Tri Artanto \\ Program Studi Desain Komunikasi Visual, \\ Fakultas Arsitektur dan Desain, UPN Veteran Jatim \\ e-mail: aryobayuw.dkv@upnjatim.ac.id
}

\begin{abstract}
Abstrak-Penelitian pada wilayah pesisir Surabaya ini bertujuan memberikan strategi branding di pesisir pantai kota Surabaya. Pemilihan penelitian di kota Surabaya dan potensi pesisir dikarenakan Pemerintah Kota Surabaya (Pemkot) membangun infrastruktur secara massif dan memiliki sustainability yang berkesinambungan dengan ekonomi dan rule model kemajuan kota Surabaya. Strategi branding pada penelitian ini perlu untuk dilakukan karena pesisir pantai kota Surabaya memiliki audiens yang loyal dan masa depan yang menjanjikan untuk di kembangkan oleh Pemkot Surabaya. Oleh karena itu hal tersebut membutuhkan kajian yang tepat agar sistem branding kedepan mampu di implementasikan ke tahapan yang mendalam. Pengumpulan data pada penelitian ini akan menggunakan kuantitatif dengan di dukung data kualitatif, yakni metode kuesioner sebagai pengumpulan data utama sedangkan wawancara, observasi dan data teks sebagai pendukung data pada penelitian ini. Pada penelitian branding pesisir ini akan melingkupi daerah yang terdampak pembangunan oleh Pemkot Surabaya, daerah tersebut adalah Kecamatan Tambak Wedi, Kecamatan Bulak dan Kecamatan Kenjeran.
\end{abstract}

Kata kunci: Branding, pesisir pantai Surabaya, Bulak, Pemkot Surabaya

\begin{abstract}
This research in the coastal area of Surabaya aims to find a branding strategy in the coastal city of Surabaya. The selection of research in the city of Surabaya and coastal potential is due to the Surabaya City Government (Pemkot) building massive infrastructure and relating to the economy and progress of the city of Surabaya. The branding strategy in this research needs to be done, because the coastal city of Surabaya has a loyal audience and has the potential to be developed by the Surabaya City Government. Therefore, this requires an appropriate study so that future branding systems are able to be implemented in depth. Data collection in this study will use quantitative supported by qualitative data. Through the questionnaire method as the main data collection, while interviews, observation and text data as supporting data in this study. The scope of this research will cover areas developed by the Surabaya City Government, these areas are Kecamatan Tambak Wedi, Kecamatan Bulak and Kecamatan Kenjeran.
\end{abstract}

Keywords: Branding, coast of Surabaya, Bulak, Surabaya city governmen

\section{PENDAHULUAN}

Kota Surabaya adalah salah satu kota metropolitan di Indonesia, memiliki penduduk yang majemuk dan memiliki potensi di dunia industri. Kota Surabaya memiliki keterkaitan dengan perekonomian kota-kota di sekitarnya dalam bentuk formal atau non formal. Pada tahun 2003 pemerintah Indonesia membangun jembatan Suramadu (Surabaya dan Madura) yang menghubungkan Pulau Jawa dan Pulau Madura, tujuannya tidak saja menjadi simbol bagi kota namun diharapkan dapat menambah pendapatan atau devisa bagi provinsi dan kota Surabaya. Untuk mendukung perubahan daerah-daerah di sekitar suramadu, maka di bangunlah sejumlah infrastruktur dan fasilitas. Pada Peraturan Daerah Kota Surabaya no. 12 tahun 2014 tentang Tata Ruang Wilayah Kota Surabaya dijabarkan tentang rencana pengembangan kawasan pesisir Surabaya untuk menjadi kawasan strategis Kota Tepi Pantai sebagai waterfront city dan sebagai embrio pusat pertumbuhan ekonomi (Pasal 67,1e). Wilayah pesisir Pantai Surabaya yang menjadi target utama pengembangan oleh pemerintah kota Surabaya, adalah Kecamatan Bulak dan Kecamatan Kenjeran, kedua kecamatan ini di prioritaskan dalam pembangunan nya karena memiliki potensi yang bisa dikembangkan di kemudian hari (Gambar 1 dan Gambar 2).

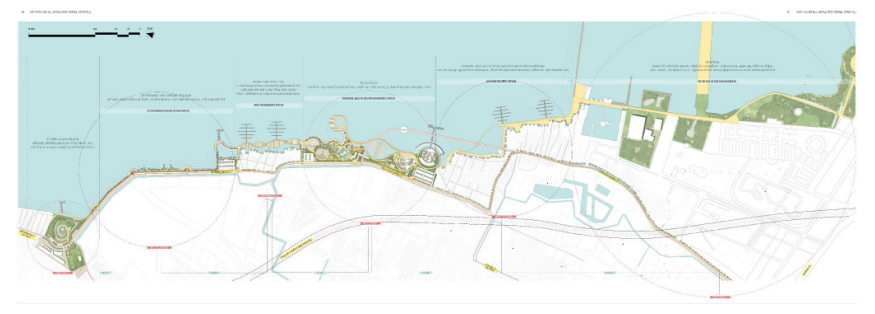

Gambar 1. Arahan Visi Pengembangan Penataan Master Plan Kawasan Pesisir Kenjeran (sumber: Bappeko Surabaya).

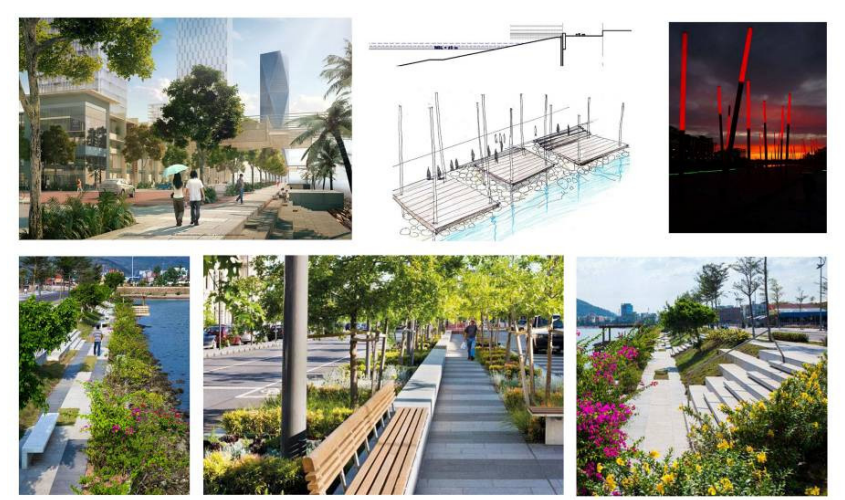

Gambar 2. Arahan Visi Pengembangan Penataan Master Plan Kawasan Pesisir Pantai Surabaya (sumber: Bappeko Surabaya).

Pada wilayah pantai kota Surabaya ini memiliki beragam keunggulan untuk dikembangkan, mulai dari potensi 
makanan ringan (camilan), ikan segar, wisata bahari dan view landscape pantai. Potensi dari wilayah pantai kota Surabaya ini menyebar di beberapa titik, sehingga wisatawan yang datang ke lokasi harus mencari tahu informasiinformasi terkait wisata di daerah pesisir pantai Surabaya. Tabel 1 menjelakskan uraian dari observasi di wilayah yang akan diteliti, terkait potensi wilayah Kecamatan Bulak dan Kecamatan Kenjeran yang menjadi keunggulan.

Table 1. Potensi wilayah dan masyarakat

\begin{tabular}{|c|c|c|c|c|}
\hline No. & $\begin{array}{c}\text { Kecama- } \\
\text { tan }\end{array}$ & $\begin{array}{c}\text { Potensi } \\
\text { Wilayah }\end{array}$ & $\begin{array}{c}\text { Pembangunan } \\
\text { Pemkot }\end{array}$ & $\begin{array}{c}\text { Potensi } \\
\text { Wisata/ } \\
\text { Lokal } \\
\end{array}$ \\
\hline \multirow[t]{5}{*}{1} & \multirow[t]{5}{*}{$\begin{array}{l}\text { Kecama- } \\
\tan \text { Bulak }\end{array}$} & \multirow{2}{*}{$\begin{array}{l}\text { Wisata Alam } \\
\text { Pantai dan } \\
\text { Kam } \\
\text { pung } \\
\text { Nelayan }\end{array}$} & $\begin{array}{l}\text { Pembangunan } \\
\text { wilayah kampung } \\
\text { Nelayan }\end{array}$ & $\begin{array}{l}\text { Nelayan, dan } \\
\text { perajin Kapal } \\
\text { tradisional, } \\
\text { spot fotografi }\end{array}$ \\
\hline & & & $\begin{array}{l}\text { Dermaga wisata } \\
\text { Kapal di tengah } \\
\text { pantai }\end{array}$ & $\begin{array}{l}\text { Pantai Pasir } \\
\text { di Tengah } \\
\text { Laut }\end{array}$ \\
\hline & & \begin{tabular}{|l} 
Jemba \\
$\tan$ \\
Surabaya
\end{tabular} & $\begin{array}{l}\text { Alur wisata ke } \\
\text { oleh-oleh produk } \\
\text { laut }\end{array}$ & $\begin{array}{l}\text { Pedagang, } \\
\text { Spot } \\
\text { fotografi, } \\
\text { wisata pantai }\end{array}$ \\
\hline & & $\begin{array}{l}\text { Produk } \\
\text { olahan ikan }\end{array}$ & $\begin{array}{l}\text { Sentra Ikan Bulak } \\
\text { (SIB) }\end{array}$ & $\begin{array}{l}\text { Pedagang } \\
\text { Ikan segar, } \\
\text { dan camilan } \\
\text { olahan ikan }\end{array}$ \\
\hline & & $\begin{array}{l}\text { Taman } \\
\text { Kenjeran }\end{array}$ & $\begin{array}{l}\text { Ikon Suro dan } \\
\text { Boyo, Taman } \\
\text { bermain keluarga }\end{array}$ & $\begin{array}{l}\text { Wisata } \\
\text { murah, } \\
\text { education } \\
\text { park. }\end{array}$ \\
\hline \multirow[t]{2}{*}{2} & \multirow[t]{2}{*}{$\begin{array}{l}\text { Kecama } \\
\tan \\
\text { Kenjeran }\end{array}$} & \multirow{2}{*}{$\begin{array}{l}\text { Jemba } \\
\text { Tan } \\
\text { Suramadu, } \\
\text { wisata laut, } \\
\text { Benteng } \\
\text { Kedung } \\
\text { Cowek }\end{array}$} & \multirow[t]{2}{*}{$\begin{array}{l}\text { Jembatan, akses } \\
\text { jalan }\end{array}$} & $\begin{array}{l}\text { Pedagang dan } \\
\text { perajin Kapal } \\
\text { tradisional, } \\
\text { Spot fotografi }\end{array}$ \\
\hline & & & & $\begin{array}{l}\text { Pedagang } \\
\text { ikan segar, } \\
\text { UMKM }\end{array}$ \\
\hline
\end{tabular}

Pada sisi lain muncul permasalahan-permasalahan dalam pembangunan infrastruktur dan ruang publik di kawasan pesisir Pantai Surabaya. Salah satu temuan dalam penelitian ini adalah pembangunan infrastruktur di wilayah pesisir tidak di imbangi dengan sistem perekonomian yang saling terintegrasi pada masyarakat sekitar. Dampak dari hal tersebut adalah masyarakat lokal mengambil peran sebagai pekerja kasar seperti Juru Parkir, atau pedagang asongan yang tidak mendukung dalam sistem perbaikan atau kemajuan wilayah pesisir [1]. Bahkan menurut observasi dilapangan, warga pendatang juga banyak yang bekerja dengan profesi yang sama. Akibatnya muncul parkir liar, kembali kotornya lingkungan yang sudah di revitalisasi, dan kemudian munculnya konflik-konflik kepentingan antara kelompok, atau etnis karena disparitas pendapatan antar kelompok atau etnis di pesisir pantai Surabaya. Untuk menghindari hal-hal tersebut pembangunan pada infrastruktur pada suatu daerah harus selaras dengan perbaikan ekonomi masyarakat, karena dengan memaksimalkan potensi yang saling bersinergi akan mengurangi disparitas diantara masyarakat [2] dan [3].

Sebenarnya Pemkot Surabaya sudah berupaya untuk membuat slogan "Sunrise of Bulak" dan membuat event yang mampu bersinergi antara pedagang ikan pesisir, institusi kampus dan pemerintah. Namun tagline dan event tersebut kurang memiliki added value dan sustainability program. Salah satunya contohnya adalah tagline "Sunrise of Bulak" jika dianalisa ulang memiliki kesamaan dengan kota Banyuwangi yang berjuluk "Sunrise of Java" yang sudah ada sejak tahun 2015. Proses transfer komunikasi inilah yang tentunya menyulitkan brand image yang di implementasikan oleh Pemkot Surabaya untuk dapat berjalan dengan baik [4]. Akibatnya kebiasaan hal-hal yang negatif masih melekat pada pendapat audiens yakni pesisir pantai yang kotor, bau dan semrawut [5].

Berdasarkan temuan permasalahan pada penelitian ini, inovasi yang dilakukan adalah memaksimalkan peran branding wilayah yang tepat untuk membuat suatu kesatuan desain yang terintegrasi mulai dari potensi lokal seperti makanan, building, dan human resources [6]. Selain itu branding dalam temuan penelitian ini adalah solusi untuk menyatukan permasalahan yang hadir di sosial masyarakat [7]. Manifesto branding wilayah agar tepat menurut Marzano \& Scott [8] adalah dengan memaksimalkan potensi yang telah dimiliki oleh masyarakat dan menggabungkan dengan kebijakan pemerintah dan serta harus memberikan dampak yang signifikan kepada perekonomian di masyarakat lokal, mulai dari level bawah hingga level atas [9].

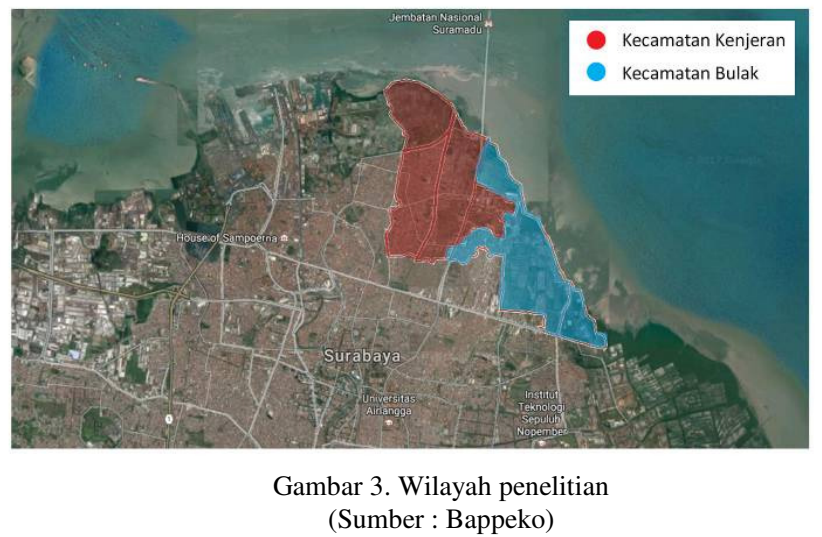

Lingkup dalam penelitian ini akan di fokuskan ke dua wilayah yang menonjol pada pesisir pantai di Surabaya yakni Kecamatan Bulak dan Kenjeran. Kedua kecamatan ini di pilih karena memiliki rangkaian dalam pengembangan water front city oleh Pemkot Surabaya. Selain itu luas wilayah dua kecamatan diatas sudah memiliki brand image yang sudah di ingat oleh audiens secara umum (Gambar 3).

\section{METODE PENELITIAN}

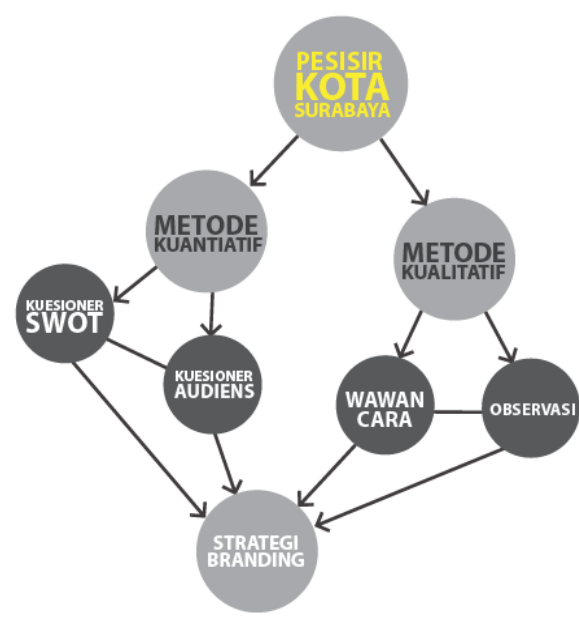

Gambar 4. Pola metodologi penelitian. 
Model metodologi dalam penelitian ini akan menggunakan metode penelitian kuantitatif di dukung oleh kualitatif [10]. Metode penelitian kuantitatif ini menggunakan pengumpulan data berupa kuesioner, tujuannya adalah pertama membuat pemetaan SWOT di wilayah pesisir pantai Surabaya dengan melibatkan 100 responden, dan kedua mencari tahu pandangan atau pendapat audiens tentang daerah pesisir pantai kota Surabaya melibatkan yang melibatkan 55 responden. Metode pengambilan sampling yang kedua akan di lakukan secara acak pada kota-kota di luar kota Surabaya, dan kota Surabaya sebagai langkah mengetahui prilaku audiens terkait aktifitas, ketertarikan dan pendapat.

Tabel 2. Target audiens pesisir pantai Surabaya

\begin{tabular}{|c|c|}
\hline \multirow[t]{2}{*}{ Demografi } & $\begin{array}{l}\text { Target Primer: (Unisex) } \\
\text { 1. Usia 35-45 tahun } \\
\text { 2. Agama: seluruh agama } \\
\text { 3. Pendidikan: minimum lulusan S1 } \\
\text { 4. Pekerjaan: Wiraswasta, PNS, guru, } \\
\text { nelayan, pedagang, dan karyawan }\end{array}$ \\
\hline & $\begin{array}{l}\text { Target Sekunder : (Unisex) } \\
\text { 1. Usia 20-35 tahun } \\
\text { 2. Agama: seluruh agama } \\
\text { 3. Pendidikan: Minimum lulusan SMA } \\
\text { 4. Pekerjaan: Mahasiswa, wiraswasta, PNS, } \\
\text { guru, nelayan, pedagang, dan karyawan }\end{array}$ \\
\hline Psikografi & $\begin{array}{l}\text { Audiens yang menjadi acuan penelitian ini } \\
\text { adalah adalah laki-laki dan perempuan yang } \\
\text { pernah berkunjung di pesisir Kenjeran dan } \\
\text { berinteraksi dengan kawasan wisata tersebut. } \\
\text { Psikografi memiliki pengalaman dan } \\
\text { kecintaan terhadap wisata, dan aktif pada } \\
\text { kegiatan traveling. }\end{array}$ \\
\hline Geografis & $\begin{array}{l}\text { Target audiens di dalam aspek penelitian ini } \\
\text { adalah masyarakat yang hidup di kota dan } \\
\text { hidup dengan teknologi dan arus informasi } \\
\text { yang memadai }\end{array}$ \\
\hline Behavior & $\begin{array}{l}\text { Peneliti melakukan pengambilan data dengan } \\
\text { memperhatikan cara berinteraksi dengan } \\
\text { produk-produk lokal, wisata-wisata di daerah } \\
\text { pesisir Kenjeran, dengan cara mendatangi } \\
\text { langsung melihat-lihat cara audiens } \\
\text { berinteraksi }\end{array}$ \\
\hline
\end{tabular}

Pada metode kualitatif terbagi menjadi dua tahapan yakni, pertama adalah untuk mendapatkan data-data terkait pandangan, simbol-simbol, ikon, keunggulan dan trade mark warga pesisir pantai kota Surabaya, kedua adalah melakukan observasi di lapangan untuk merekam dan melakukan uji hipotesis terkait asumsi dan pengumpulan data sebelumnya, serta observasi data-data dari Pemkot dan Badan Perencanaan dan Pengembangan Kota (Bappeko) Surabaya (Gambar 4, Tabel 2). Setelah melewati pengumpulan data maka tahap berikutnya adalah melakukan brainstorming, yakni membuat uji desain melalui tahap penggalian ide dan pembuatan prototype desain [11].

\section{HASIL DAN PEMBAHASAN}

\section{Observasi dan wawancara}

Aktifitas observasi pada penelitian di lapangan adalah merekam, mencatat dan melakukan wawancara ke warga lokal. Temuan observasi pada penelitian ini untuk menentukan variabel yang akan digunakan untuk pengumpulan data strategi internal-eksternal dan kebutuhan merancang logo pada branding

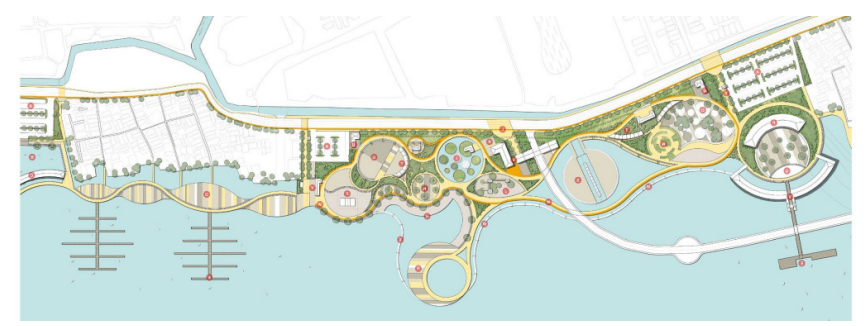

Gambar 5. Pengembangan wilayah pesisir pantai Surabaya tahun 2025 (Sumber : Bappeko)

Pada pesisir pantai Surabaya telah dibuat brand dengan tagline "Sunrise of Bulak" tagline ini diperkenalkan melalui beberapa media. Pada analisa dan temuan data pada teks tagline pesisir pantai kota Surabaya memiliki kesamaan dengan tagline kota Banyuwangi yang bernama "sunrise of java" yang artinya kurang lebih adalah "kota Banyuwangi adalah lokasi tempat matahari terbit di Pulau Jawa". Hal tersebut menjadikan tagline "sunrise of bulak" menjadi kurang begitu relevan lagi jika dipakai untuk tagline atau slogan di media promosi, sehingga perlu re-design tagline yang kuat dalam branding pesisir (Gambar 5).

Pada observasi di lapangan profesi masyarakat di pesisir adalah melakukan aktifitas Nelayan, pedagang ikan, pedagang krupuk ikan dan pegawai di suatu institusi pada perusahaan atau pemerintahan. Selain itu menurut data observasi di lapangan infrastruktur sudah sesuai dengan rencana pembangunan, mulai dari jembatan, perdagangan, pemukiman, reklamasi pantai dan termasuk yang terbaru adalah pembangunan ikon Surabaya di taman (suro dan boyo).

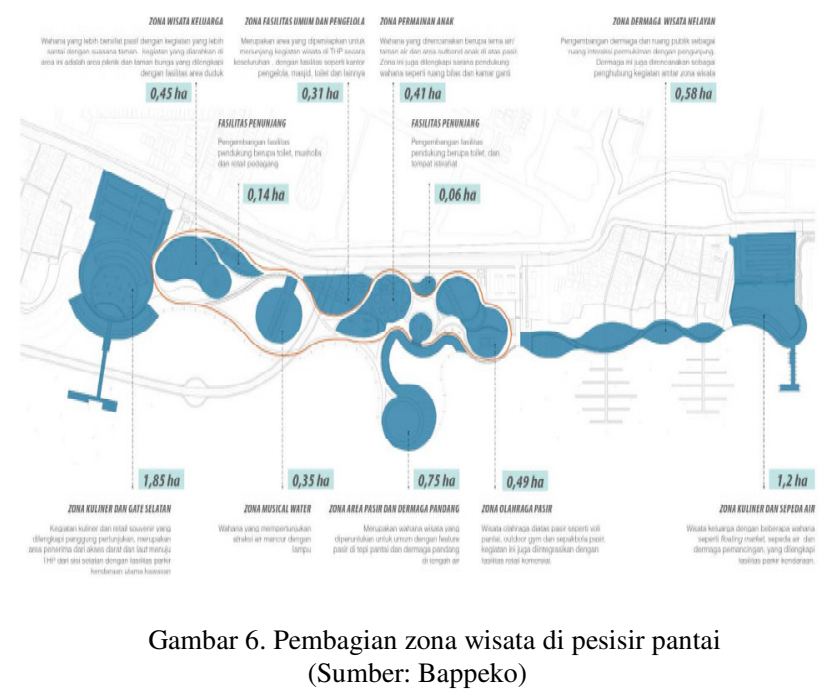

Pada data observasi lainnya menurut sumber dari Bappeko, di pesisir pantai kota Surabaya sudah dibagi-bagi dan di ploting alur dan konsepnya. Misalnya saja zona wisata keluarga, zona bermain, zona UMKM, zona lingkungan hidup dan zona wisata pantai. Tiap zona terbagi menjadi 0,31 Ha hingga 2,1 Ha, hal ini disesuaikan dengan 
kebutuhan dan cakupan wilayah yang dapat digunakan (Gambar 6).

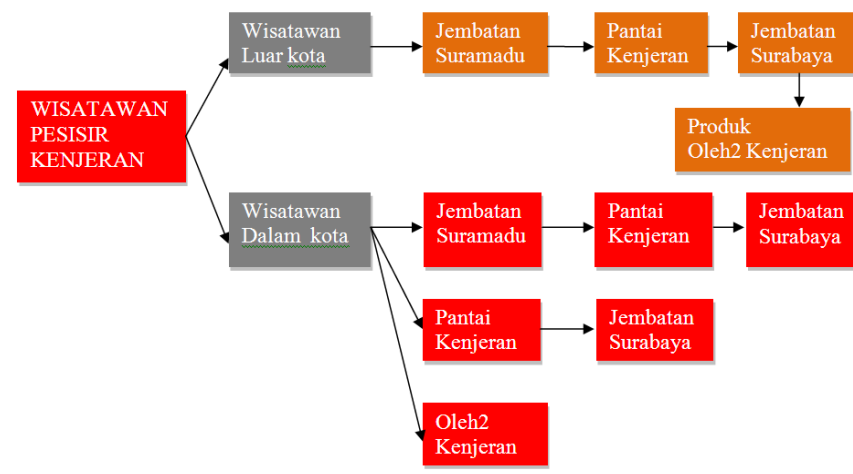

Gambar 7. Alur wisatawan di pesisir pantai Surabaya.

Pada alur wisatawan yang hadir ke pesisir pantai Surabaya ketika di lakukan analisa observasi dan dilakukan wawancara ke masyarakat memiliki alur seperti dapat dilihat pada Gambar 7.
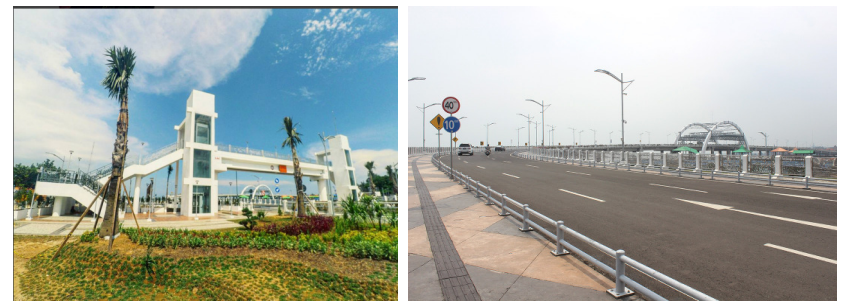

Gambar 8. Jembatan Suroboyo dan fasilitas Lift.
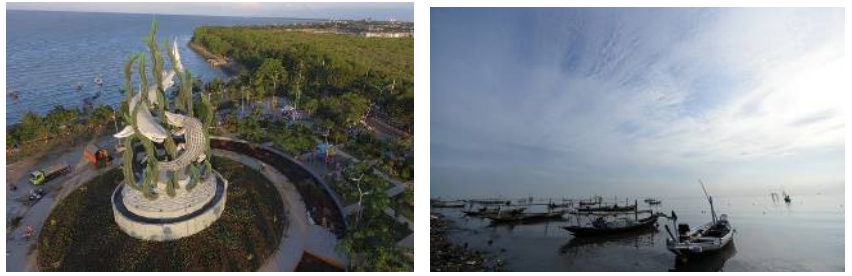

Gambar 9. Zona Pantai Yang selesei dibangun dan Kampung Nelayan. (Gambar : Surabaya Tribun News (1) ; Olahan Pribadi (2))
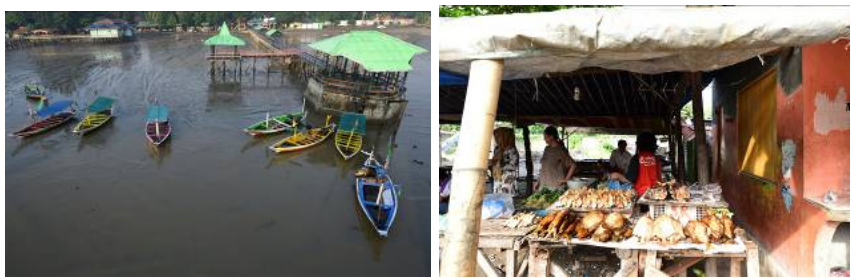

Gambar 10. Kapal untuk wisata laut dan pedang ikan asap.
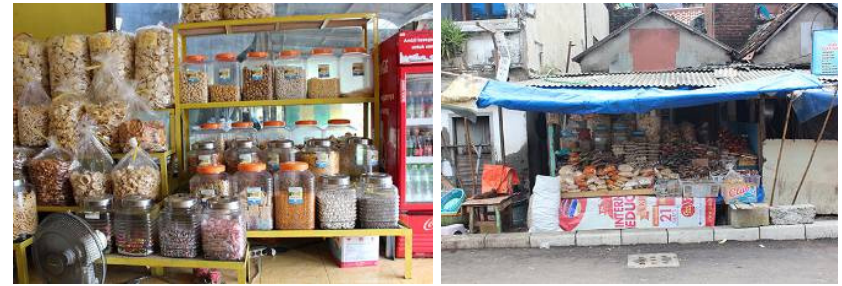

Gambar 11. Pedagang camilan dan kerupuk ikan.
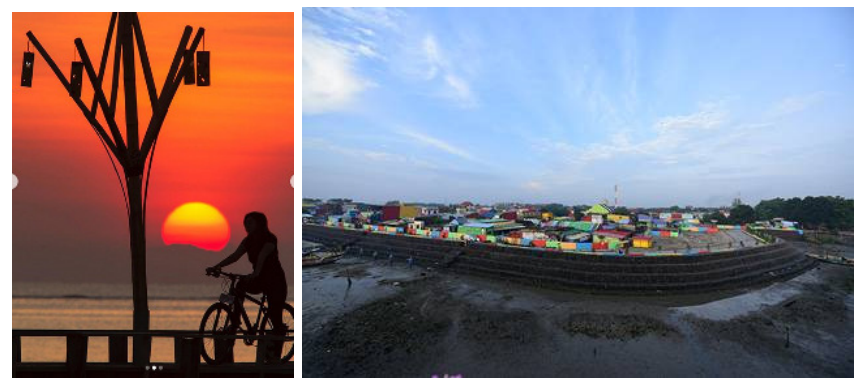

Gambar 12. Spot wisata Fotografi, dan kampung warna-warni Nelayan pesisir (Gambar : Instagram Yuyung Abdi (1), Olahan Pribadi (2))

Potensi-potensi pada pesisir pantai di Kecamatan Bulak dan Kenjeran memiliki banyak keunggulan dari segi pengembangan di berbagai sektor. Hal ini dapat kita lihat pada selesainya infrastruktur, akses dan wisatawan yang kian bertambah hingga tahun 2019. Menurut data dari Bappeko akses dan tempat akan saling terhubung dengan wisatawan yang hadir. Beberapa temuan dapat kita lihat pada Gambargambar 8, 9, 10, 11 dan 12 .

\section{Analisa Strength, Weakness, Opportunity, dan Threat (SWOT)}

Pengelompokkan variabel SWOT menjadi dua yakni faktor internal (strength, weakness) dan eksternal (Opportunity, Threat). Faktor internal meliputi skala sumber daya fisik (bangunan, kekuatan/potensi daerah), sumber daya manusia, sumber daya keuangan (perputaran uang yang ada di suatu daerah, atau pendapatan perkapita keluarga) dan sumber daya intangibles. Sedangkan variabel eksternal meliputi teknologi, ekonomi, sosial budaya, politik dan pasar/perdagangan. Pengelompokan ini yang akan di jadikan ukuran untuk melihat kekuatan, kelemahan, potensi dan ancaman yang menonjol di pesisir pantai kota Surabaya melalui analisa SWOT (Tabel-tabel 3, 4, 5, 6 dan 7).

Pemetaan SWOT terkait potensi wilayah pesisir pantai kota Surabaya diatas menurut variabel strength dan weakness menunjukan kekuatan utama ada pada sumber daya fisik seperti pembangunan infrastruktur yang memadai untuk mendukung kemajuan wilayah. Sedangkan faktor kelemahan daerah di pesisir pantai kota Surabaya ditunjukan pada sumber daya keuangan yang berarti pendapatan tiap keluarga dan alur keuangan yang tidak stabil mengingat rendahnya sumber daya manusia yang dimiliki. Selain itu faktor yang dianggap memiliki bobot rendah pada analisa diatas adalah sumber daya yang tidak nampak (intangibles) seperti pesisir pantai Surabaya yang memiliki kawasan kampung Nelayan, dan image pesisir kota metropolitan yang belum dimaksimalkan.

Pada variabel opportunity dan threat faktor teknologi memiliki nilai tinggi, hal ini dapat diartikan teknologi di infrastruktur dapat bersinergi dengan baik sehingga membentuk peluang pada akses informasi yang nantinya mampu menjadikan daerah pesisir menjadi lebih dikenal. Faktor lain yang memiliki skor rendah adalah bagian Sosial Budaya pada dimensi regulasi antar nelayan terkait operasional kapal wisata dan melaut. Hal ini menunjukan jika disparitas pendapatan menjadi krusial di wilayah Kecamatan Bulak dan Kenjeran (Gambar 13) 
Tabel 3. Tabel Strategi Strength

\begin{tabular}{|c|c|c|c|c|c|}
\hline \multicolumn{2}{|r|}{ Faktor Strategi Internal } & \multirow{2}{*}{ B } & \multirow{2}{*}{$\mathbf{K S}$} & \multirow{2}{*}{$\mathbf{R}$} & \multirow{2}{*}{$\mathbf{S}$} \\
\hline V & Dimensi & & & & \\
\hline \multirow{7}{*}{ 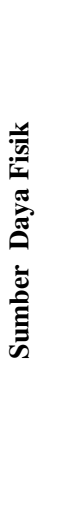 } & $\begin{array}{l}\text { Potensi perikanan bagi } \\
\text { kota Surabaya }\end{array}$ & 3 & 0.068 & 3.290 & 0.224 \\
\hline & $\begin{array}{l}\text { Ketersediaan hasil } \\
\text { tangkapan ikan segar }\end{array}$ & 3 & 0.068 & 3.210 & 0.219 \\
\hline & $\begin{array}{l}\text { Ketersediaan olahan } \\
\text { ikan asap khas pesisir } \\
\text { Kota Surabaya }\end{array}$ & 3 & 0.068 & 3.180 & 0.217 \\
\hline & $\begin{array}{l}\text { Hadirnya Sentra Ikan } \\
\text { Bulak (SIB) }\end{array}$ & 3 & 0.068 & 3.100 & 0.211 \\
\hline & $\begin{array}{l}\text { Memiliki kawasan } \\
\text { Sentra Kuliner }\end{array}$ & 1 & 0.023 & 3.040 & 0.069 \\
\hline & Pengolahan kulit kerang & 1 & 0.023 & 3.100 & 0.070 \\
\hline & $\begin{array}{l}\text { Hadirnya objek wisata } \\
\text { seperti di ruang publik }\end{array}$ & 3 & 0.068 & 3.600 & 0.245 \\
\hline \multirow{5}{*}{ 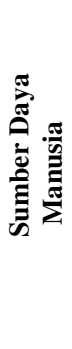 } & Komunitas Nelayan & 3 & 0.068 & 3.220 & 0.220 \\
\hline & $\begin{array}{l}\text { Kehidupan nelayan dan } \\
\text { daya tarik wisata }\end{array}$ & 3 & 0.068 & 3.080 & 0.210 \\
\hline & $\begin{array}{l}\text { Pemukiman Nelayan } \\
\text { yang mulai bebenah }\end{array}$ & 3 & 0.068 & 3.230 & 0.220 \\
\hline & $\begin{array}{l}\text { Pengecatan warna warni } \\
\text { rumah warga }\end{array}$ & 3 & 0.068 & 3.160 & 0.215 \\
\hline & $\begin{array}{l}\text { Pedagang/ } \\
\text { UMKM Kerupuk }\end{array}$ & 3 & 0.068 & 3.320 & 0.226 \\
\hline \multirow{3}{*}{ 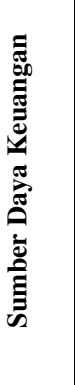 } & $\begin{array}{l}\text { Pengembangan } \\
\text { pemukiman dan } \\
\text { fasilitas nelayan } \\
\text { /pedagang ikan }\end{array}$ & 3 & 0.068 & 3.470 & 0.237 \\
\hline & $\begin{array}{l}\text { pihak swasta (LSM) dan } \\
\text { Bank yang mendukung } \\
\text { di sektor UMKM }\end{array}$ & 1 & 0.023 & 3.340 & 0.076 \\
\hline & $\begin{array}{l}\text { Adanya program } \\
\text { Pemkot utk } \\
\text { mengembangkan wisata } \\
\text { bahari }\end{array}$ & 3 & 0.068 & 3.390 & 0.231 \\
\hline \multirow[b]{2}{*}{ 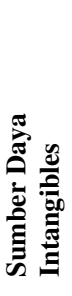 } & $\begin{array}{l}\text { Satu-satunya kawasan } \\
\text { pengembangan wisata } \\
\text { Bahari di Kota } \\
\text { Surabaya } \\
\end{array}$ & 3 & 0.068 & 3.360 & 0.229 \\
\hline & $\begin{array}{l}\text { Kawasan pesisir } \\
\text { Kenjeran adalah } \\
\text { alternatif wisata dengan } \\
\text { harga murah }\end{array}$ & 2 & 0.045 & 3.540 & 0.161 \\
\hline & JUMLAH & 44 & 1.000 & 55.63 & 3.282 \\
\hline
\end{tabular}

Tabel 4. Strategi Weakness

\begin{tabular}{|c|c|c|c|c|c|}
\hline \multicolumn{2}{|r|}{ Faktor Strategi Internal } & \multirow{2}{*}{ B } & \multirow{2}{*}{ KS } & \multirow{2}{*}{$\mathbf{R}$} & \multirow{2}{*}{$\mathbf{S}$} \\
\hline $\mathbf{V}$ & Dimensi & & & & \\
\hline \multirow{5}{*}{ 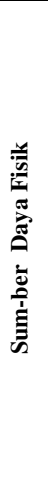 } & $\begin{array}{l}\text { Kurangnya lahan parkir } \\
\text { dikawasan pesisir untuk } \\
\text { wisatawan }\end{array}$ & 1 & 0.077 & 2.460 & 0.189 \\
\hline & $\begin{array}{l}\text { Kurangnya fasilitas } \\
\text { umum di lokasi wisata } \\
\text { seperti toilet dan } \\
\text { musholla } \\
\end{array}$ & 1 & 0.077 & 2.500 & 0.192 \\
\hline & $\begin{array}{l}\text { Sentra Ikan Bulak masih } \\
\text { sepi pembeli }\end{array}$ & 3 & 0.231 & 2.930 & 0.676 \\
\hline & $\begin{array}{l}\text { Beberapa pedagang ikan } \\
\text { masih berjualan } \\
\text { dipinggir }\end{array}$ & 1 & 0.077 & 2.990 & 0.230 \\
\hline & $\begin{array}{l}\text { Kondisi air laut yang } \\
\text { masih kotor }\end{array}$ & 2 & 0.154 & 2.880 & 0.443 \\
\hline
\end{tabular}

Tabel 5. Strategi Weakness(Lanjutan)

\begin{tabular}{|c|c|c|c|c|c|}
\hline \multicolumn{2}{|r|}{ Faktor Strategi Internal } & \multirow{2}{*}{ B } & \multirow{2}{*}{ KS } & \multirow{2}{*}{$\mathbf{R}$} & \multirow{2}{*}{$\mathbf{S}$} \\
\hline V & Dimensi & & & & \\
\hline \multirow{2}{*}{ 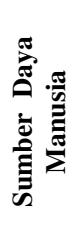 } & $\begin{array}{l}\text { Kurangnya kesadaran } \\
\text { masyarakat akan } \\
\text { kebersihan }\end{array}$ & 1 & 0.077 & 2.440 & 0.188 \\
\hline & $\begin{array}{l}\text { Tingkat pendidikan } \\
\text { yang rendah di } \\
\text { pemukiman nelayan }\end{array}$ & 1 & 0.077 & 2.360 & 0.182 \\
\hline 离 & $\begin{array}{l}\text { Pengembangan kawasan } \\
\text { pesisir Kenjeran sebagai } \\
\text { destinasi wisata belum } \\
\text { berpengaruh terhadap } \\
\text { pendapatan nelayan } \\
\text { kawasan pesisir }\end{array}$ & 1 & 0.077 & 2.830 & 0.218 \\
\hline 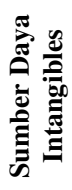 & $\begin{array}{l}\text { Pemukiman Nelayan } \\
\text { masih memiliki kesan } \\
\text { kumuh dan amis }\end{array}$ & 2 & 0.154 & 2.110 & 0.325 \\
\hline & Jumlah & 13 & 1.000 & 23.5 & 2.642 \\
\hline
\end{tabular}

Tabel 6. Strategi Opportunity

\begin{tabular}{|c|c|c|c|c|c|}
\hline \multicolumn{2}{|c|}{ Faktor Strategi Internal } & \multirow{2}{*}{ B } & \multirow{2}{*}{$\mathbf{K S}$} & \multirow{2}{*}{$\mathbf{R}$} & \multirow{2}{*}{$\mathbf{S}$} \\
\hline $\mathbf{V}$ & Dimensi & & & & \\
\hline \multirow{5}{*}{ 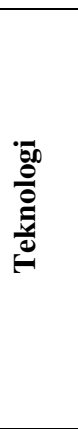 } & $\begin{array}{l}\text { Kunjungan mahasiswa } \\
\text { Universitas untuk } \\
\text { penyuluhan }\end{array}$ & 2 & 0.059 & 3.060 & 0.180 \\
\hline & $\begin{array}{l}\text { Hadirnya infrastruktur } \\
\text { di pesisir pantai }\end{array}$ & 3 & 0.088 & 3.270 & 0.289 \\
\hline & $\begin{array}{l}\text { Hadirnya penerangan } \\
\text { jalan }\end{array}$ & 2 & 0.059 & 3.800 & 0.224 \\
\hline & $\begin{array}{l}\text { Adanya sign system } \\
\text { sebagai penanda lokasi } \\
\text { kawasan wisata pesisir }\end{array}$ & 3 & 0.088 & 3.290 & 0.290 \\
\hline & $\begin{array}{l}\text { Pemanfaatan teknologi } \\
\text { internet }\end{array}$ & 1 & 0.029 & 2.820 & 0.083 \\
\hline \multirow{4}{*}{ 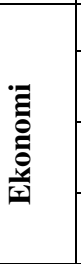 } & Kebijakan MEA. & 3 & 0.088 & 3.050 & 0.269 \\
\hline & $\begin{array}{l}\text { Pengembangan sektor } \\
\text { ekonomi Kelautan }\end{array}$ & 3 & 0.088 & 3.060 & 0.270 \\
\hline & $\begin{array}{l}\text { Pengembangan potensi } \\
\text { pariwisata }\end{array}$ & 3 & 0.088 & 2.970 & 0.262 \\
\hline & $\begin{array}{l}\text { Naiknya harga tanah } \\
\text { dan bangunan }\end{array}$ & 1 & 0.029 & 2.490 & 0.073 \\
\hline 需 & $\begin{array}{l}\text { Nilai-nilai religi (islam) } \\
\text { yang mempengaruhi } \\
\text { kebudayaan dan } \\
\text { kehidupan sosial }\end{array}$ & 1 & 0.029 & 3.540 & 0.104 \\
\hline \multirow{3}{*}{ 兴 } & $\begin{array}{l}\text { Adanya rencana } \\
\text { pembangunan rute }\end{array}$ & 3 & 0.088 & 3.170 & 0.280 \\
\hline & $\begin{array}{l}\text { Peraturan Daerah Kota } \\
\text { Surabaya No. } 12 / 2014 \\
\text { tentang rencana tata } \\
\text { ruang wilayah di pesisir }\end{array}$ & 3 & 0.088 & 3.070 & 0.271 \\
\hline & $\begin{array}{l}\text { Penataan master plan } \\
\text { kawasan pesisir } \\
\text { Kenjeran yang saling } \\
\text { terintegrasi }\end{array}$ & 3 & 0.088 & 3.080 & 0.272 \\
\hline \multirow{2}{*}{ 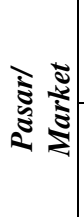 } & $\begin{array}{l}\text { Kebutuhan perikanan } \\
\text { kota Surabaya yang } \\
\text { besar }\end{array}$ & 2 & 0.059 & 2.970 & 0.175 \\
\hline & $\begin{array}{l}\text { Dampak dari Program } \\
\text { Kementrian Kelautan } \\
\text { dan Perikanan (KKP) }\end{array}$ & 1 & 0.029 & 2.680 & 0.079 \\
\hline & JUMLAH & 34 & 1.000 & 46.32 & 3.120 \\
\hline
\end{tabular}




\begin{tabular}{|c|c|c|c|c|c|}
\hline \multicolumn{2}{|c|}{ Faktor Strategi Internal } & \multirow{2}{*}{ B } & \multirow{2}{*}{$\mathbf{K S}$} & \multirow{2}{*}{$\mathbf{R}$} & \multirow{2}{*}{$\mathbf{S}$} \\
\hline $\mathbf{V}$ & Dimensi & & & & \\
\hline \multirow{3}{*}{ 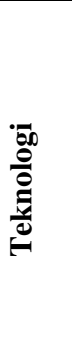 } & $\begin{array}{l}\text { Proses nelayan } \\
\text { menangkap ikan masih } \\
\text { menggunakan alat } \\
\text { tradisional }\end{array}$ & 3 & 0.130 & 2.080 & 0.271 \\
\hline & $\begin{array}{l}\text { Proses pengolahan ikan } \\
\text { yang masih tradisional }\end{array}$ & 3 & 0.130 & 2.070 & 0.270 \\
\hline & $\begin{array}{l}\text { Proyek reklamasi yang } \\
\text { dapat merusak } \\
\text { ekosistem laut }\end{array}$ & 3 & 0.130 & 2.250 & 0.293 \\
\hline \multirow{4}{*}{ 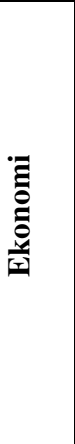 } & $\begin{array}{l}\text { Kenaikan harga bahan } \\
\text { bakar }\end{array}$ & 1 & 0.043 & 2.440 & 0.106 \\
\hline & $\begin{array}{l}\text { Mahalnya harga } \\
\text { peralatan menangkap } \\
\text { ikan }\end{array}$ & 1 & 0.043 & 2.440 & 0.106 \\
\hline & $\begin{array}{l}\text { Pengolahan hasil ikan } \\
\text { memanfaatkan dari } \\
\text { hasil tangkapan nelayan } \\
\text { daerah lain }\end{array}$ & 1 & 0.043 & 2.050 & 0.089 \\
\hline & $\begin{array}{l}\text { Biaya maintenance } \\
\text { kapal untuk nelayan } \\
\text { yang mahal }\end{array}$ & 1 & 0.043 & 2.450 & 0.107 \\
\hline \multirow{2}{*}{ 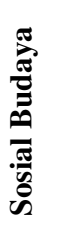 } & $\begin{array}{l}\text { Anggapan negatif } \\
\text { masyarakat }\end{array}$ & 3 & 0.130 & 3.460 & 0.451 \\
\hline & $\begin{array}{l}\text { Adanya regulasi antar } \\
\text { kampung nelayan untuk } \\
\text { kapal }\end{array}$ & 1 & 0.043 & 1.920 & 0.083 \\
\hline \multirow{2}{*}{ 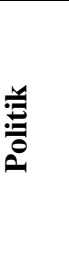 } & $\begin{array}{l}\text { Persaingan di bidang } \\
\text { kelautan dengan daerah } \\
\text { lain }\end{array}$ & 2 & 0.087 & 1.810 & 0.157 \\
\hline & $\begin{array}{l}\text { Persaingan dengan } \\
\text { daerah lain yang } \\
\text { memiliki potensi } \\
\text { UMKM }\end{array}$ & 2 & 0.087 & 1.830 & 0.159 \\
\hline \multirow[t]{2}{*}{ 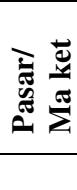 } & $\begin{array}{l}\text { Persaingan SIB dengan } \\
\text { Pasar Pabean sebagai } \\
\text { tempat penjualan ikan } \\
\text { dan hasil olahan ikan }\end{array}$ & 2 & 0.087 & 1.990 & 0.173 \\
\hline & JUMLAH & 23 & 1.000 & 26.79 & 2.267 \\
\hline
\end{tabular}

$* \mathrm{~V}=$ Variabel ; $\mathrm{B}=$ Bobot $; \mathrm{KB}=$ Konversi Bobot ; $\mathrm{R}=$ Rating $; \mathrm{S}=$ Skor

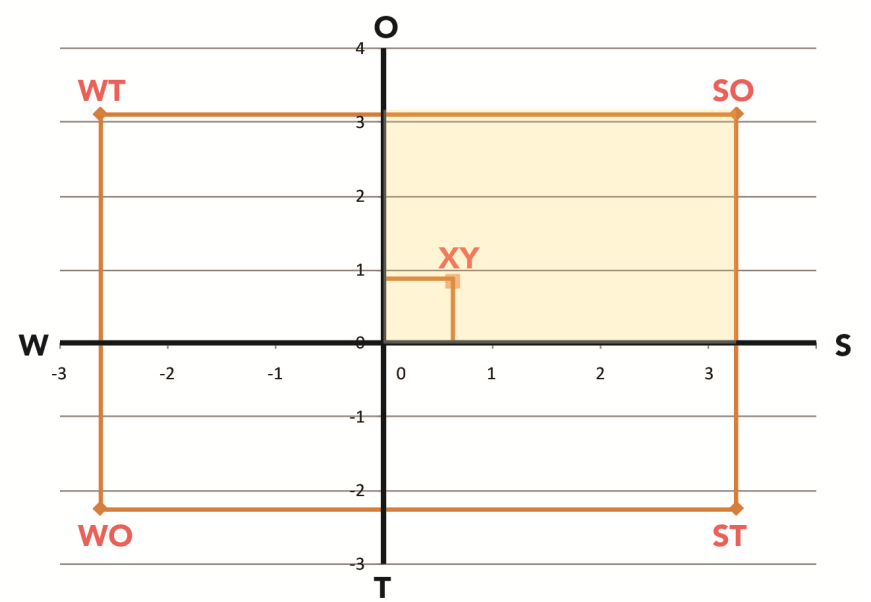

Gambar 13. Kesimpulan analisa SWOT.
Menurut dari hasil penghitungan tabel diatas, didapatkan koordinat SWOT Matriks sebagai berikut :

- SO $(3.282,3.120) \quad$ - ST $(3.282,-2.267)$

- WT (-2.642, -2.267) - WO (-2642, 3.120)

Koordinat titik XY adalah posisi di pesisir pantai kota

Surabaya yang didapat dari :

$\mathrm{X}=$ Jumlah Rating S + Jumlah Rating W

$=3.282+(-2.642)=0.640$

$\begin{aligned} \mathrm{Y} & =\text { Jumlah Rating O + Jumlah Rating } \mathrm{T} \\ & =3.120+(-2.267)=0.853\end{aligned}$

Kesimpulan analisa SWOT pada hasil kesimpulan menunjukan pada posisi koordinat I. Kesimpulan analisa pada pesisir pantai di kota Surabaya pada hasil SWOT memiliki strategi yang harus diprioritaskan adalah strategi Strenght dan Opportunity (SO), yaitu strategi yang menggunakan kekuatan untuk memanfaatkan peluang. Peluang ini adalah pembangunan sejumlah fasilitas dan infrstrukturnya. Selain itu peluang di pesisir pantai sudah seharusnya pemerintah dan pihak-pihak terkait mengoptimalkan kondisi teknologi yang terstruktur dan saling bersinergi. Sehinga kedua point ini akan masuk dalam tahap pengembangan branding kedepannya.

\section{Persepsi audiens}

Menurut data dalam penyebaran kuesioner ke sejumlah 55 responden yang berasal beberapa kota, pendapat audiens terkait aktifitas, ketertarikan dan opini audiens adalah sebagai berikut. Aktifitas yang menonjol di kalangan masyarakat Pesisir Pantai Kenjeran (Pedagang kerupuk ikan $32 \%$; Aktifitas Nelayan 26,6\% ; Aktifitas pedagang ikan 19,2\% ; Aktifitas pengolahan ikan 19,2\% ; sisanya lain-lain). Fasilitas Ruang Publik sudah lebih baik (Ya 80,8 ; tidak 19,2 $\%)$. Fasilitas yang paling sering digunakan adalah, Jembatan Suramadu, Jembatan Suroboyo dan Kapal Nelayan. Paling sering ke wisata pesisir (Keluarga 80,8\%, dengan rekan/teman $15,4 \%$, sisanya dengan istri/suami). Tujuan favorit ketika berada disana adalah (Membeli hasil laut seperti camilan, Ikan asap, Kerupuk dsb 40,4\%, menggunakan fasilitas umum $30,8 \%$, menikmati alam pantai $19,2 \%$, Olahraga, ke waterpark, berinteraksi dengan warga/nelayan 6\%).

Transportasi audiens ketika pergi ke pantai pesisir Surabaya adalah (Mobil 63,5\%, Motor 32,7\%, sepeda dan ojek online $3,8 \%$ ). Waktu ke pesisir pantai kota Surabaya paling cocok (Pagi hari 51,9\%, Sore Hari 42,3\%, malam hari $5,8 \%$ ). Lokasi yang di kunjungi terlebih dahulu ketika ke pesisir pantai (pergi ke Sentra Ikan Bulak (SIB) dan toko camilan 26,9\%, Pantai 25\%, Jembatan suroboyo 23,1\%, Jembatan Suramadu 19,2\%, Taman, Pantai Ria dll 5,8\%). Oleh-oleh yang diketahui sebagai khas pesisir (kerupuk terung $82,1 \%$, rambak $17,9 \%$ ). Karakter yang kuat pada masyarakat pesisir Kenjeran Surabaya (Mengolah ikan $73,1 \%$, bahasa khas pesisir $13,5 \%$, Nelayan 9,6\%, kerajinan dll $3,8 \%$ ). Kerupuk ikan terung merupakan yang paling favorit sebagai oleh-oleh $(59,5 \%)$, Ikan asap $(31,4 \%)$, dan lainnya seperti kerang dll $(9,1 \%)$.

Menurut pendapat audiens karakter masyarakat/Orang pesisir (Tegas, lugas, berani 48,1\%, Ramah, sopan dan baik $32,7 \%$, acuh dan cuek 13,5\%, Tegas berwibawa, lugu 5,7\%). Kalimat positif yang terlintas di benak audiens ketika 
mendengar pesisir pantai Surabaya adalah (Kerupuk terung $69,5 \%$, prosentase yang lain adalah wisata, tempat keluarga, pantai dll, masing - masing 1\%). Sedangkan kalimat negatif yang terlintas di benak audiens adalah (kotor $60,1 \%$, berbau amis 25,5\%, tempat mesum 9,5\%, Tempat etnis Madura $4,9 \%$ ).

\section{KESIMPULAN/RINGKASAN}

Strategi branding untuk pesisir kota Surabaya memiliki beberapa faktor penting yang harus diperhatikan, faktor faktor itu adalah sebagai berikut,

1. Manusia,

Masyarakat di pesisir pantai Surabaya memiliki dua etnis, yakni Jawa dan Madura. Karakteristik kedua etnis ini tidak jauh berbeda pada segi prilaku dan karakter maanusianya. Oleh karena itu faktor branding nantinya harus memiliki latar belakang yang harus memfungsikan masyarakat di pesisir agar memiliki sisi optimis dan bersinergi dengan pembangunan yang di lakukan oleh Pemkot kota Surabaya.

2. Sosial dan Budaya

Masyarakat di pesisir pantai kota Surabaya memiliki model percampuran budaya Jawa dan Madura. Sehingga tidak jarang dialetika masyarakat pesisir bercampur, sehingga sulit untuk menentukan apakah warga asli atau pendatang. Namun perbedaan ini menjadi identitas tersendiri di dalam sifat dan karakter sehari - hari. Selain itu budaya Islam juga sangat kuat di masyarakat pesisir, sehingga perlu menggunakan pendekatan - pendekatan kearah islami jika nantinya strategi branding diterapkan.

3. Hunian dan Infrastruktur

Lokasi tempat tinggal masyarakat pesisir rata - rata kumuh dan kotor, namun pada beberapa sektor tampak sudah berbenah dan Pemkot memberikan bantuan kepada beberapa wilayah untuk dibenahi. Maka strategi branding yang diterapkan nantinya harus mencakup aspek hunian, dan harus bersinergi dengan konsep infrastruktur Pemkot. Sehingga hunian/tempat tinggal warga pesisir mampu dioptimalkan melalui skema branding.

4. Teknologi

Pada era sekarang ini teknologi menjadi hal yang wajib bagi pola berkomunikasi, oleh karena itu agar memiliki konotasi wisata yang maju maka daerah pesisir harus memiliki sistem teknologi yang mampu menjangkau warga dan wisatawan agar dapat dimanfaatkan untuk keperluan dan mendukung pariwisata [13].

5. Perdagangan dan Pemasaran

Perdagangan di pesisir pantai kota Surabaya dari tahun ke tahun mengalami disintegrasi kepercayaan ke Pemkot. Akibatnya Sentra Ikan Bulak (SIB) tidak terlalu di perhatikan oleh warga. Perdagangan akhirnya di lakukan di sepanjang jalan pantai, namun Pemkot dan pengelola seharusnya melihat peluang lain yang harus di manfaatkan dengan adanya situasi ini sehingga tidak menimbulkan kontra dan friksi yang hadir di tengah - tengah masyarakat. selain itu model pemasaran dalam perdagangan sudah seharusnya memiliki sistem, integrasi dan cara yang efektif. Hal ini agar produk - produk olahan, atau produk mentah di pesisir dapat dimanfaatkan oleh masyarakat luas. Dalam hal ini maka pemilihan media harus efektif dan tepat guna, selain itu dapat diproduksi oleh masyarakat secara mandiri sehingga dapat membuka peluang-peluang bisnis bagi masyarakat sekitar.

\section{UCAPAN TERIMA KASIH}

Terimakasih kami ucapkan pada segenap dosen- dosen prodi Fakultas Arsitektur dan Desain, civitas akademika Prodi Desain Komunikasi Visual (DKV UPNV Jawa Timur) yang telah membantu dalam pengumpulan data dan keterlibatan selama dua tahun penelitian kami di pesisir pantai kota Surabaya. Kami juga mengucapkan terimakasih kepada pihak -pihak yang membantu memfasilitasi penelitian ini antara lain adalah instansi Pemkot Surabaya, Bappeko Kota Surabaya dan Kecamatan Bulak dan Kenjeran serta Humas Kartar Kota Surabaya.

\section{DAFTAR PUSTAKA}

[1] Rhofita, E. I \& Naily, N. "Persepsi Komunitas Nelayan Kenjeran Terhadap Kegiatan Konservasi Lingkungan Pesisir Berdasarkan Perspektif Ekoteologi Islam”. JPLB, 2018, 2(2):112-124 ISSN 2598-0017 I E-ISSN 2598-0025 (2018) http://www.bkpsl.org/ojswp/index.php/jplb.

[2] Srivinasu. B \& P., Srinivasa Rao. Infrastructure Development and Economic growth : Prospects and Perspective. "Journal of Business Management \& Social Sciences Research" (JBM\&SSR) ISSN No: 2319-5614 Volume 2, No.1, January 2013. https://pdfs.semanticscholar.org/8fcd/6cb961185007b 6f929473a716fe588c0ff86.pdf.

[3] Bramwell, Bill., "Coastal Mass Tourism: Diversification And Sustainable Development In Sothern Europe”. Footprint Books Australia (2004)

[4] Kotsi F., Balakrishnan M.S, Michael. I, Ramsøy T.Z., Place Branding : Aligning Multiple Stakeholder Perception Of Visual And Auditory Communication Elements, "Journal of Destination Marketing \& Management 7", 112-130, 2018 http://dx.doi.org/10.1016/j.jdmm.2016.08.006

[5] Freeman, K., "Creating Strategic Taglines. Strategic Direction”, 21(10), 3-4. 2005, doi:10.1108/02580540510626628

[6] Berg, Per Olof \& Guje Sevón, Food-Branding Places-A Sensory Perspective," Place Branding and Public Diplomacy Journal" Vol. 01. Pages. 1-16. 2015, doi:10.1057/pb.2014.29

[7] Michelson, Aleksandr \& Katrin Paadam., "Destination Branding And Reconstructing Symbolic Capital Of Urban Heritage: A Spatially Informed Observational Analysis In Medieval Towns”, 2015. http://dx.doi.org/10.1016/j.jdmm.2015.12.002

[8] Giuseppe Marzano \& Noell Scott., Power In Destination Branding. "Annals of Tourism Research”, Journal,Vol. 36, No. 2, pp. 247-267, 2009. Elsevier ltd. doi:10.1016/j.annals.2009.01.004 
[9] Chan, C.-S., \& Marafa, L. M., "Chapter 2 Branding Places and Tourist Destinations: A Conceptualisation and Review. The Branding of Tourist Destinations: Theoretical and Empirical Insights”, 15-42, 2018. doi:10.1108/978-1-78769-373-92018100

[10] Kriyantono, Rachmat., “Teknik Praktis : Riset Komunikasi”, Jakarta Kencana Prenada Media Group (2012)

[11] Pustika, N., Mustain. M, \& Mukhtasor., “Analisis Pengelolaan Kawasan Pantai Kenjeran Berbasis
Masyarakat" (2014)

[12] Kartajaya, Hermawan., "Positioning Diferensiasi Brand: Memenangkan Persaingan dengan Segitiga”. Jakarta : PT. Gramedia Pustaka Utama (2004)

[13] Kladou, S., Kavaratzis, M., Rigopoulou, I., \& Salonika, E., "The role of brand elements in destination branding”. Journal of Destination Marketing \& Management, 6(4), 426-435, 2017. doi:10.1016/j.jdmm.2016.06.011 